\title{
SPECTROMICROSCOPY AT THE ORGANIC-INORGANIC INTERFACE IN BIOMINERALS
}

\author{
GELSOMINA DE STASIO*, MARGARET A. SCHMITT**, and \\ SAMUEL H. GELLMAN**
}

\begin{abstract}
After a brief introduction to biomineralization, we describe x-ray absorption near-edge structure (XANES) spectromicroscopy, and how this approach explores the poorly understood mechanisms of biomineral formation. In particular, XANES identifies the molecular groups forming chemical bonds at the organicinorganic interface. The first two experiments, on microbial polysaccharide-FeOOH mineralized filaments and on a synthetic peptide, are discussed.
\end{abstract}

\section{INTRODUCTION}

\section{The Organic-Inorganic Interface in Biominerals}

Biomineralization is the process by which organisms form minerals. Many biominerals are composite materials, containing a biologically produced organic matrix and nano- or micro-scale amorphous or crystalline minerals. Biomineral composite materials include bone, dentine, enamel, statoliths in the human ear, mollusk and crustacean shells, eggshells, algal and coccolith silica scales, radiolarian and diatom silica microskeletons and shells, and a variety of transition metal minerals produced by different bacteria (Banfield and Nealson, 1997; Fortin and others, 1997; Addadi and Weiner, 1997; Fitts and others, 1999; Templeton and others, 1999; Mann, 2001; Lower and others, 2001; Glasauer and others, 2002; Weiner and Dove, 2003; De Yoreo and Vekilov, 2003; De Yoreo and Dove, 2004).

Although the mechanisms of biomineral formation are not yet fully understood (for example, Mount and others, 2004), it is hoped that they may provide models for the fabrication of new materials and give new insights into the genetic control of biological structure (for example, Schäffer and others, 1997).

Biominerals provide a variety of functions to eukaryotes: protection, movement, grinding, and gravity or magnetic field sensing. Conversely, in prokaryotes, biominerals are often formed as a byproduct of a biochemical pathway, in which the bacteria oxidize or reduce transition metals or other inorganic solution species during metabolic energy generation (Banfield and Nealson, 1997).

In both cases, the complex bioinorganic chemistry involved in biomineralization constitutes a distinct evolutionary advantage for the organism performing it, which is why it became as widely spread as we observe today.

In the examples of eukaryotic biominerals given above, the biomineral products are clearly of direct benefit. In the case of microbial biomineralization, metal oxidation or reduction can be induced - or exploited - by the bacterium, but mineralization itself may have only indirect advantages or even disadvantages. Biomineral formation often occurs extracellularly, and it is subsequent to oxidation or reduction. In some cases it is detrimental: entombment of the bacterium in its own biomineral products is possible, and the cell either dies or develops an evasion strategy, such as the formation of mineral sheaths (for example, leptothrix) or stalks (gallionella) (Banfield and others, 2000).

*University of Wisconsin-Madison, Department of Physics, and Synchrotron Radiation Center, 3731 Schneider Drive, Stoughton, Wisconsin 53589; pupa@src.wisc.edu

**University of Wisconsin-Madison, Department of Chemistry, 1101 University Avenue, Madison, Wisconsin 53706. 
Many biomineralization mechanisms are poorly understood at the molecular level. These include all cases in which highly oriented crystals are formed with control over the particular crystal phase (polymorph) that is grown (De Yoreo and Dove, 2004). Shell, bone and some bacterial filaments are examples of such biomineralization: a highly specialized organic matrix directs the formation of a specific crystal phase and orientation. In these composites the organic-inorganic interaction is so specialized that a templation mechanism can be invoked. The particular matrix of organic molecules, produced by the living organism, acts as a template upon which crystals grow epitaxially, that is, growth is nucleated, and crystal structure, phase, orientation and often habit of the mineral are determined by the organic matrix.

It is conceivable that at the molecular scale, the organic molecule binds a few ions, which serve as nucleation site for crystal growth. Self-assembly and epitaxial crystal growth subsequently complete the composite structure, by filling the voids in the three dimensional organic matrix. Exploitation of such templation mechanisms, therefore, can be considered as a "genome shortcut", naturally selected to minimize the amount of information that the organism needs to transfer down the lineage, while maximizing the performance of the final composite material. Specifically, self-assembly and epitaxial crystal growth are harnessed by the organism, therefore the only necessary genetic information involves the production of the organic matrix.

From a materials science point of view, organic molecules are usually soft, but compliant and fracture resistant. Inorganic crystals are hard, but usually brittle. Biomineral composites exploit the best of these properties, and minimize the weaknesses: they are hard and fracture resistant. Nacre, for instance, is 3000 times tougher than geological aragonite! (Currey, 1977; Jackson and others, 1988; Schäffer and others, 1997).

Materials scientists have only recently begun to learn how to build a synthetic composite material that outperforms each component taken separately, and have done so inspired by shell nacre (Tang and others, 2003).

Nacre, or mother-of-pearl, of mollusk shells and pearls is a microlaminate composite of highly oriented calcium carbonate $\left(\mathrm{CaCO}_{3}\right)$ crystals and proteins (fig. 1), which exhibits exceptional regularity and mechanical strength (Mann, 2001). Nacre is an organic-inorganic composite, containing $500 \mathrm{~nm}$ thick aragonite (orthorhombic $\mathrm{CaCO}_{3}$ ) crystal plates interspersed as "bricks" between organic matrix sheets, or "mortar" (Currey, 1977; Jackson and others, 1988; Schäffer and others, 1997). The organic matrix is composed of silk-like proteins and glycoproteins. These are, therefore, expected to be the templating molecules.

One interesting hypothesis explored by many authors is that the negatively charged amino acids along the protein sequences, aspartate and glutamate, attract positive ions from solution, and initiate crystal nucleation and growth (Mann, 2001; Weiner and Dove, 2003). This hypothesis deserves further investigation. We hereafter present preliminary data obtained from a synthetic polypeptide rich in glutamate, that binds Ca from solution.

A novel set of tools is necessary to discover exactly which molecules interact at the organic-inorganic interface, and at which specific molecular sites the first chemical bonds are formed, that is, how biomineral formation begins. X-ray spectromicroscopy, used in combination with other microscopic and biological methods, is one such novel tool to begin to unravel the chemistry of templation mechanisms.

\section{Spectromicroscopy}

Until recently, templation mechanisms have not been studied with x-ray absorption near edge structure (XANES) spectroscopy. The understanding of organicinorganic templates can be expanded by using XANES, because this powerful chemical 


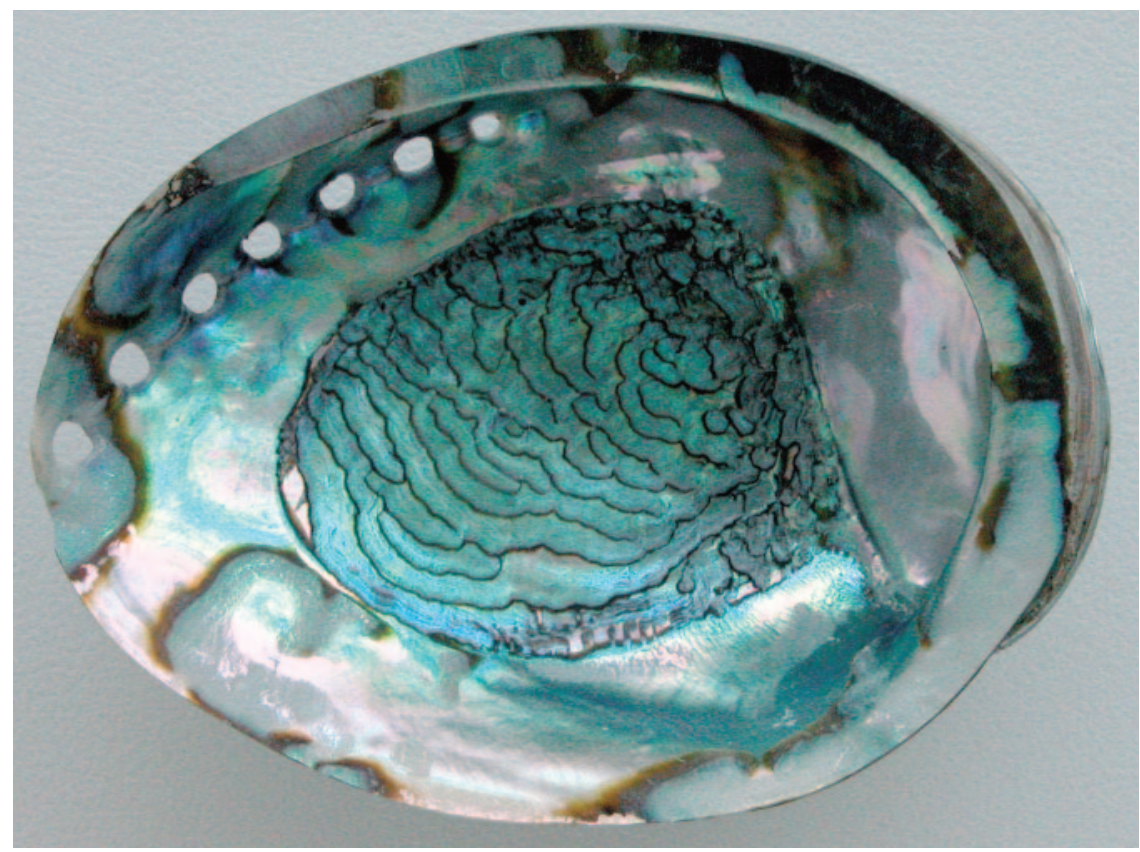

Fig. 1. Photograph of the nacreous inside face of an abalone shell (Haliotis rufescens). The shell width is approximately $20 \mathrm{~cm}$.

analysis is sensitive to elemental composition, oxidation state, coordination number, and crystal or molecular structure of minerals and organic molecules (Stöhr, 1992).

XANES has been successfully used to reveal the presence and oxidation state of specific elements in geologic minerals (Sturchio and others, 1998), the structure of synthetic materials (Bozek and others, 1990), elemental speciation in soils and sediments (Myneni and others, 1997; Beauchemin and others, 2003; Zawislanski and others, 2003) and other environmentally relevant samples (Myneni and others, 1999; Myneni, 2002a).

Many other experiments on the microlocalization of trace elements in eukaryotic cells (De Stasio and others, 1993, 1996; Gilbert and others, 2000; De Stasio and others 2001) and the identification of prokaryotic biomineral products (Labrenz and others, 2000; Lopez-Garcia and others, 2003; Lawrence and others, 2003; Chan, De Stasio and others, 2004), also attest to the power and breadth of XANES spectroscopy and spectromicroscopy.

The lineshapes of XANES spectra correspond to the molecular and/or crystal structures surrounding the elements under analysis. However, interpretation of the spectral lineshape, and peak assignment can be complicated.

When the molecular or crystal structure is known, and relatively simple, ab initio calculations are used to simulate the XANES spectrum. A comparison of experimental and calculated spectra enables peak assignment to specific molecular structures. Specific peaks can be considered "spectral signatures" of specific molecular features. XANES is extremely sensitive to carbon chemistry: examples of molecular features generating well established spectral signatures are $\mathrm{C} \equiv \mathrm{C}, \mathrm{C}=\mathrm{C}, \mathrm{C}-\mathrm{O}, \mathrm{C}=\mathrm{O}, \mathrm{C}-\mathrm{O}$, as well as C-C-C bond angles, conjugation of adjacent bonds, et cetra. A material that contains several of these molecular features exhibits a XANES spectrum resulting from 


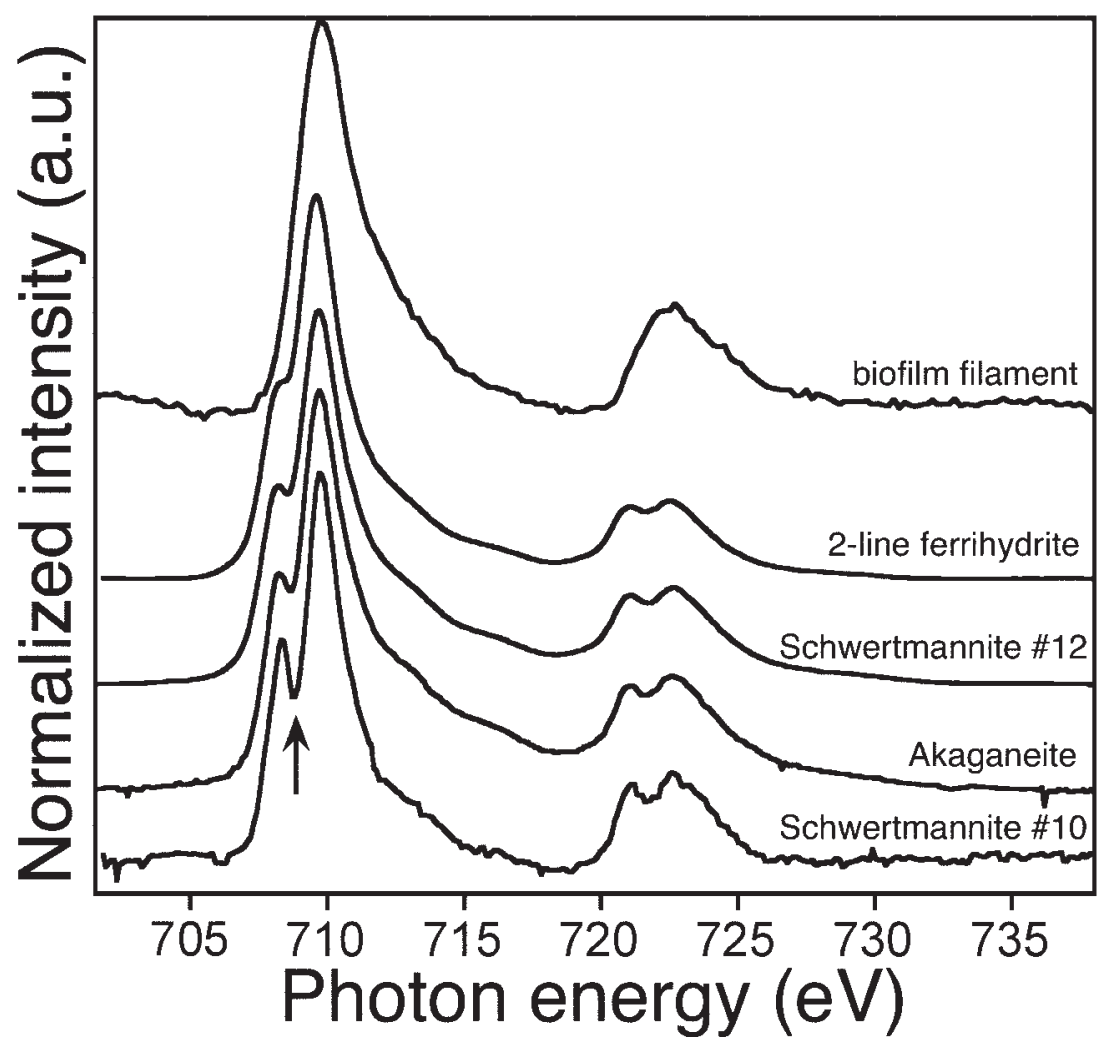

Fig. 2. Top: Fe L-edge XANES spectra of the FeOOH mineralized looped filament shown in figure 5B, produced by an iron-oxidizing microbe. This spectrum is compared with iron oxyhydroxide standards, arranged (top to bottom) in order of increasing crystallinity, as measured by x-ray diffraction peak narrowing. Crystalline phases have well resolved peaks at $\sim 708.4$ and $\sim 709.8 \mathrm{eV}$. As crystallinity increases the dip separating peaks (arrow) increases in depth. In the mineralized filament the lack of dip can therefore be interpreted as amorphous iron oxyhydroxide. Data from Chan, De Stasio and others, 2004.

the combination of the corresponding spectral signatures: the "building blocks" (Stöhr, 1992).

For other edges, for example, Si or S at the L-edge, simulations of XANES spectra are not currently adequate because the electronic structure is too complex to be calculated. In these cases, the spectral signatures do exist, and are measurable, but they are not univocally assigned to specific bonds or molecular structures. However, unknown minerals, such as sub-micron silicate inclusions, can still be identified by empirical comparison with spectra from known, macroscopic, reference silicate minerals (De Stasio and others, 2003; Gilbert and others, 2003).

XANES is also sensitive to crystallinity. In a recent experiment we observed for the first time a spectral signature at the Fe L-edge that measures the degree of amorphous versus crystalline mineral present in $\mathrm{Fe}^{3+}$ minerals (Chan, De Stasio and others, 2004). This signature is shown in figure 2.

Most importantly, XANES has been used to study the same kind of molecular interactions discussed hereafter, but without spatial resolution. For example, organicinorganic interaction at the binding sites in metalloproteins (Benfatto and others, 2003), or between metal ion and humic macromolecules (Myneni, 2002a). 
There are practical reasons that have completely precluded spectromicroscopy of biomineralized structure until now.

This spectroscopy can be performed by detecting fluorescence photons or photoemission electron (photoelectrons) from a solid sample surface. Fluorescence XANES signal is most intense at hard-x-ray energies, above $1 \mathrm{keV}$. However, the relevant absorption edges of organic elements $\mathrm{N}, \mathrm{C}$ and $\mathrm{O}$ are: $\mathrm{N}$ K-edge $400 \mathrm{eV}, \mathrm{C}$ K-edge at $285 \mathrm{eV}$, and $\mathrm{O}$ K-edge at $531 \mathrm{eV}$. Since none of these edges is accessible to the $\mathrm{x}$-ray fluorescence range, the organic components of biominerals have never been studied with fluorescence XANES.

Photoelectron XANES, also known as total electron yield or TEY-XANES, is much more intense than fluorescence below $1 \mathrm{keV}$, where the Ca L-edge, and the $\mathrm{C}, \mathrm{N}$ and $\mathrm{O}$ K-edges are located. In this spectral region, a strongly space-averaged TEY spectroscopy has always been possible, on an insulating biomineral. This is, however, not particularly informative, given the highly organized microscopic structure of biominerals.

Spectromicroscopy with X-ray PhotoElectron Emission Spectromicroscope (XPEEM) adds spatial resolution to the TEY experiment, down to the $10 \mathrm{~nm}$ level (Frazer and others, 2004). Until recently, however, X-PEEM could only image and analyze the chemistry of conductive sample surfaces. Insulating samples such as minerals and biominerals could not be analyzed without major charging problems.

Transmission x-ray microscopy experiments (for example, scanning transmission x-ray microscopy, STXM (Kilcoyne and others, 2003; Tyliszczak and others, 2004), which do not suffer from charging, are limited to very thin solid samples (few atomic monolayers) or dilute liquid samples. Biominerals, therefore, are excluded from this powerful analysis.

We recently optimized a differential-thickness coating method (De Stasio and others, 2003) that enabled us to extensively study mineral surfaces with X-PEEM and do high-resolution imaging and XANES analysis on them (35 $\mathrm{nm}$ or better) (Gilbert and others, 2003). We have used this coating approach on a variety of insulators, including wood, quartz, zircons, glass slides, tribological polyphosphate films and cells. In all these cases the coating completely removed charging and enabled micro- and nano-XANES spectroscopy of insulators. Figure 3 shows a representative example of the results enabled by differential-thickness coating.

X-PEEM, combining XANES spectroscopy and spatial resolution, can study the molecular interactions involved in biomineral formation. It can, potentially, analyze the organic and inorganic components of biominerals in situ. It is, therefore, the most promising technique to investigate biominerals, and understand the interactions of the organic matrix with the minerals, through their spectral signatures.

Once carbon XANES spectra from the bound, mineral-templating, and unbound organic matrices of biominerals are obtained, the difference between those spectra reveals the organic-inorganic interaction. Interpretation of the data is then done by comparison with the extensive literature on carbon XANES spectroscopy in individual amino acids and organic compounds (Stöhr, 1992; Carravetta and others, 1998; Kaznacheyev and others, 2002; Myneni, 2002b), or by comparison with reference molecules prepared ad hoc for a specific interaction.

Two experiments described below will clarify these methods.

The major weakness of the XANES X-PEEM approach is the inability to separate co-localized mixed phases. In the presence of multiple proteins in a biomineral (for example, bone), carbon K-edge spectra may be too complicated to interpret. In that case it is necessary to acquire spectra from separate single-components, and deconvolute individual contributions to XANES spectra of the mixture. Separation and/or purification of single components may not be possible. Furthermore, the components may not be spectroscopically distinguishable. If the individual organic components 


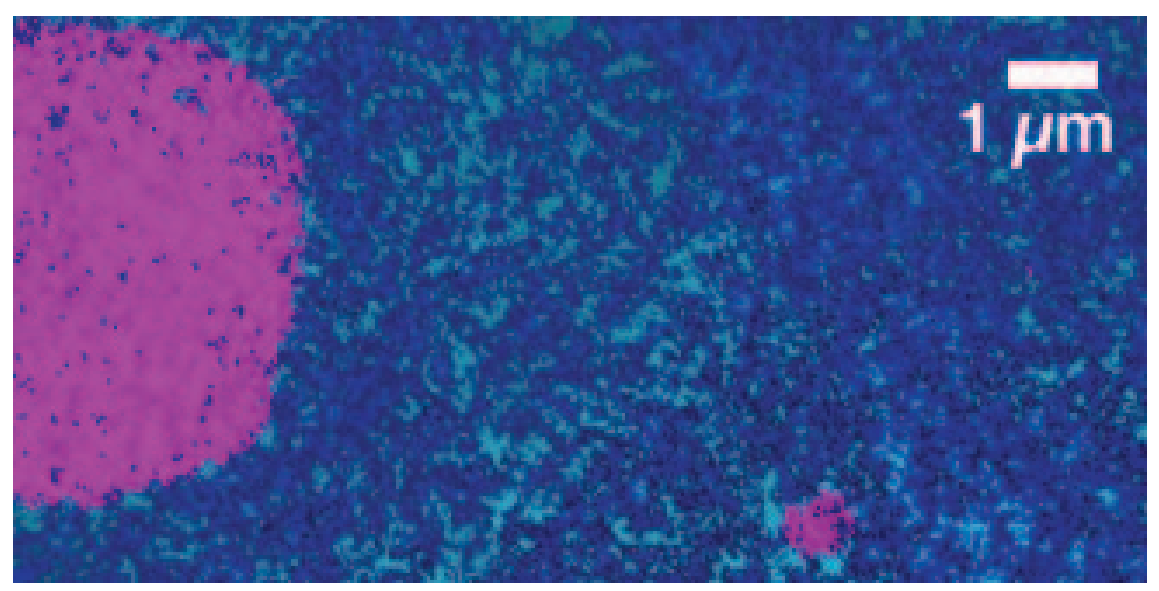

Fig. 3. Distribution maps of quartz (magenta) and zircon (blue), extracted from XANES stacks of images (each pixel contains the full Si L-edge XANES spectrum). These data were acquired using the SPHINX ${ }^{1}$ instrument, which is an X-PEEM (Frazer and others, 2004), on the polished surface of the oldest zircon known - 4.4 billion year old (Wilde and others, 2001) - and superimposed on the direct image of the same zircon (cyan). The quartz map shows quartz inclusions in the zircon. The smaller inclusion is $800 \mathrm{~nm}$ in diameter: too small to be analyzed with any other non-destructive technique. (Data from De Stasio and others, 2003).

contributing to XANES spectra are known and spectroscopically distinct, singular value decomposition, or cluster analysis methods can be used to deconvolute and quantify their contributions (Pickering and others, 2000; Lerotic and others, 2004).

RESULTS AND DISGUSSION

\section{First Experimental Observation of an Organic-Inorganic Template: Bacterial Polysaccharides and Akaganeite}

We recently analyzed a mineral structure in which an organic-inorganic template is the only possible explanation for the formation of the crystal observed (Chan, De Stasio and others, 2004).

Iron-oxidizing bacteria, that have not yet been isolated nor phylogenetically identified, induce the formation of unprecedented $\sim 2 \mathrm{~nm}$ wide, up to 10 micronlong, curved pseudo-single crystals of akaganeite (b-FeOOH) in the cores of filaments. The filaments are 20 to $200 \mathrm{~nm}$ wide, tangled, and composed of 2-line ferrihydrite $\left(\mathrm{FeOOH} \cdot \mathrm{nH}_{2} \mathrm{O}\right)$, surrounding the akaganeite cores (fig. 4). Formation of akaganeite in solution requires the presence of chloride, and is unexpected in fresh water. We therefore suggested that the mechanism of akaganeite formation requires templation by organic polymers extruded by the bacteria (Chan, De Stasio and others, 2004).

A key step in the formation of the akaganeite filament cores is the formation of chemical bonds between an organic molecule and solution or precipitated species, precursors to the inorganic crystal. As in many other biominerals, the organic molecule acts as a template for a particular mineral polymorph.

We first analyzed the polymer fibrils extruded from the bacterial cell membrane, using the SPHINX X-PEEM (Frazer and others, 2004), and identified them as

\footnotetext{
${ }^{1}$ Spectromicroscope for PHotoelectron Imaging of Nanostructures with X-rays (SPHINX), installed on the High Energy Resolution MONochromator (HERMON) beamline, at the Wisconsin-Synchrotron Radiation Center.
} 


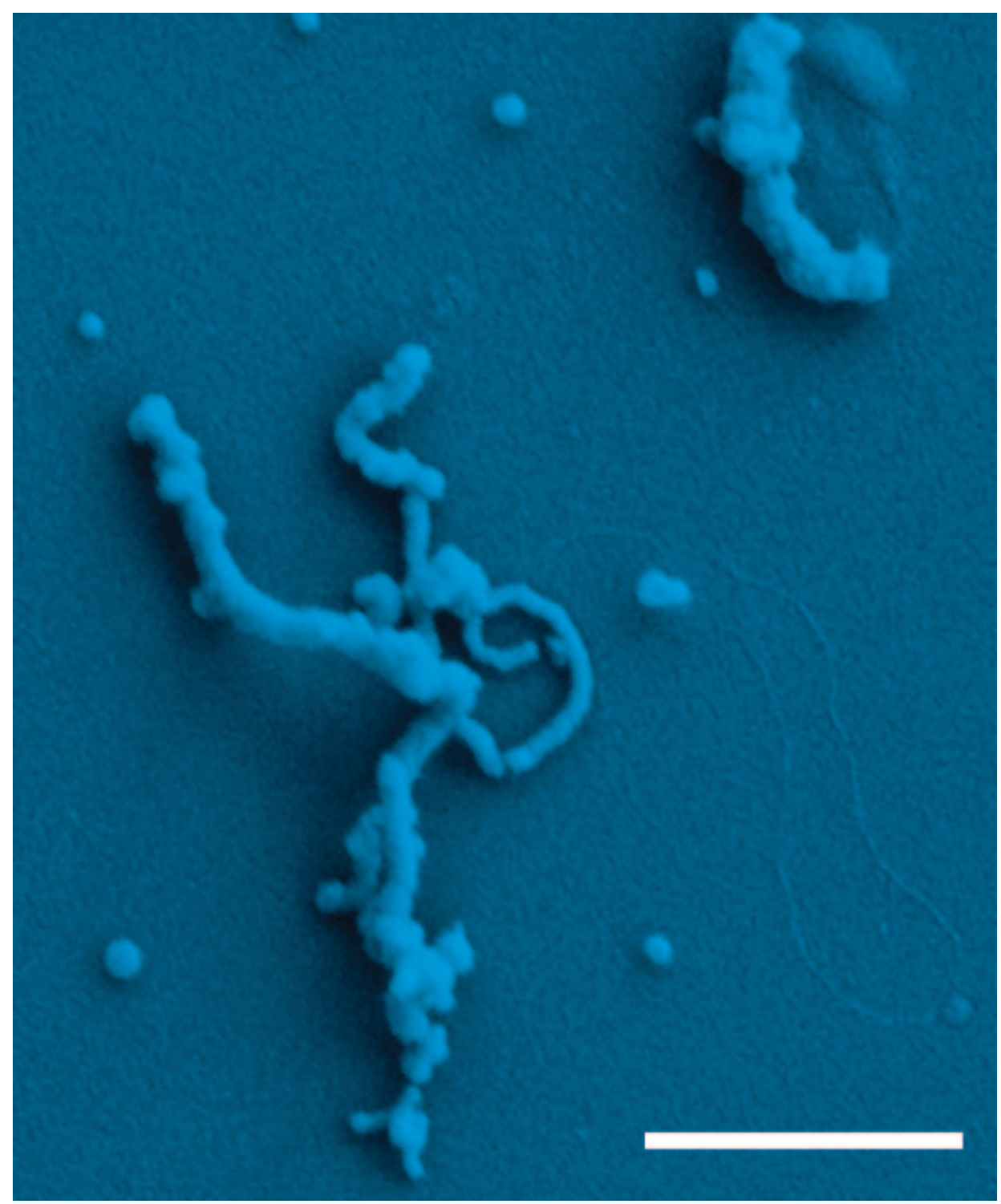

Fig. 4. SEM image of mineralized filaments produced by Fe-oxidizing bacteria in the Piquette abandoned and flooded mine in Tennyson, WI. The filaments, approximately $100 \mathrm{~nm}$ in diameter are mineralized by $\mathrm{FeOOH}$ adhesion to the polysaccharide chains immediately after being extruded by the bacterium. On the right hand-side of the image a thinner, faint, strand is visible, possibly a non-mineralized polysaccharide fibril. Scale bar is $1 \mu \mathrm{m}$. (Imaged by B. H. Frazer and G. De Stasio)

polysaccharides by comparison of their carbon K-edge XANES spectra, with those from representative reference compounds (fig. 5).

We then analyzed the mineralized filaments from the biofilm. These also revealed a polysaccharide spectrum at the carbon K-edge. $\mathrm{FeOOH}$ nanoparticles formed an $\sim 50 \mathrm{~nm}$ thick coating around the polysaccharide fibrils, hence the carbon signal was much lower, relative to the $\sim 2 \mathrm{~nm}$ diameter uncoated filaments. 

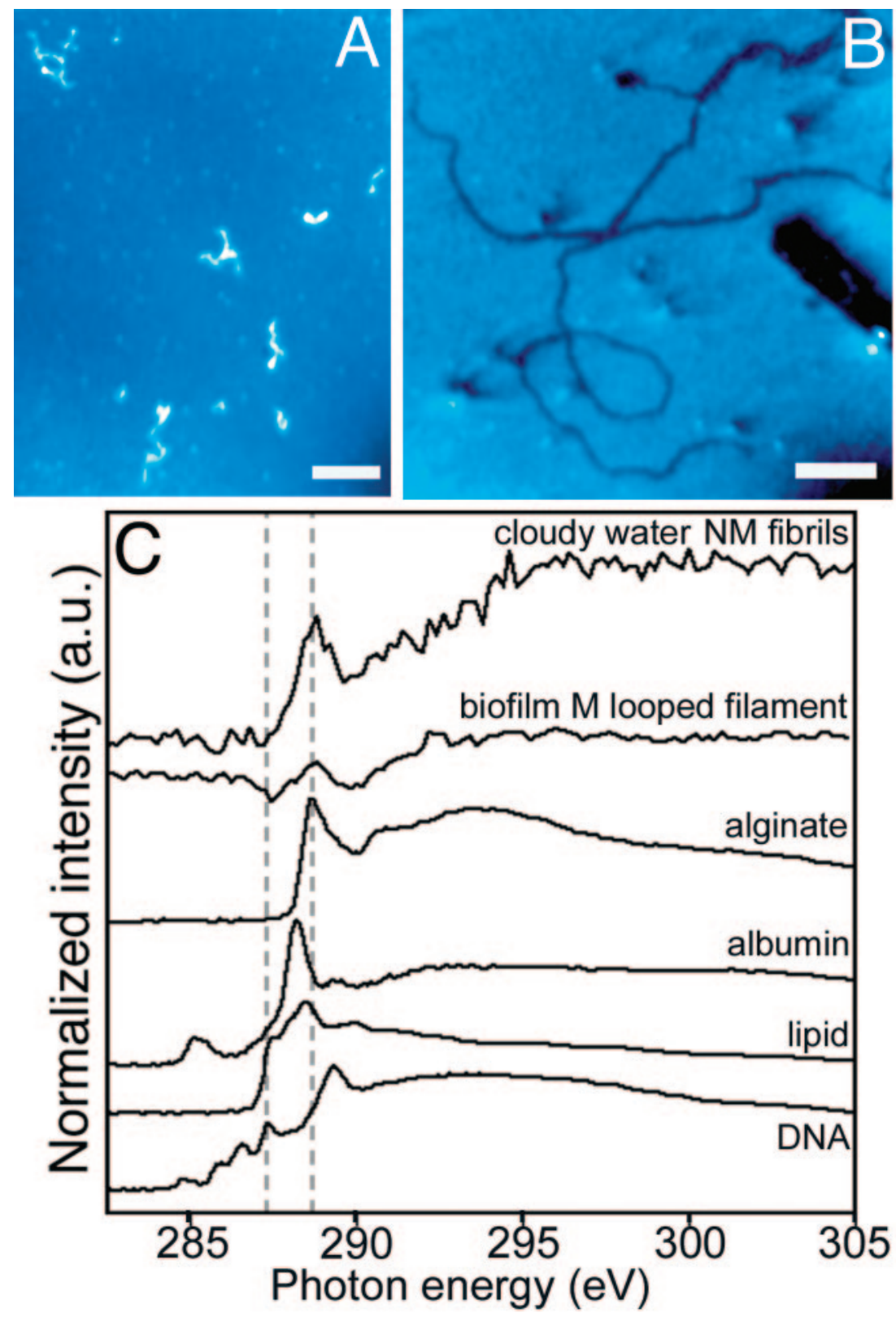

Fig. 5. SPHINX images and spectra of the filaments produced by iron-oxidizing bacteria. (A) Image of non-mineralized polymer fibrils from the cloudy water above the biofilm (5 $\mu \mathrm{m}$ scale bar) and (B) mineralized filaments from the biofilm ( $1 \mu \mathrm{m}$ scale bar). These, and all other mineralized filaments in the biofilm, contain the akaganeite crystal core described in the text. (C) Carbon K-edge XANES spectra from multiple non-mineralized (NM) fibrils in (A), the single, looped, $100 \mathrm{~nm}$ wide, mineralized (M) filament in (B), and reference organic molecules: sodium alginate (acidic polysaccharide); albumin (protein); a single chain C-16 saturated lipid; and calf thymus DNA. The dashed lines at $287.3 \mathrm{eV}$ and $288.6 \mathrm{eV}$ highlight the energy position of the most characteristic peaks for DNA and alginate. Notice the similarity of the spectra from the NM fibrils and M filaments with the polysaccharide spectrum, and the additional structure in the one from the M filament: the peak at $292.4 \mathrm{eV}$ was assigned to the $\mathrm{C}-\mathrm{O}$ bond in carboxyl groups. Data from Chan, De Stasio and others, 2004. 
With regard to biomineralization, the most relevant result of that experiment is that carbon spectroscopy from mineralized filaments revealed a new peak, which was never present in spectra from the non-mineralized polysaccharide strands. This spectral signature was interpreted as a $\mathrm{s}^{*}$ resonance of a $\mathrm{C}-\mathrm{O}$ single bond involved in $\mathrm{FeOOH}$ binding. It is likely that the $\mathrm{C}-\mathrm{O}$ groups that interact with $\mathrm{FeOOH}$ originate from the carboxyl groups $\left(\mathrm{O}=\mathrm{C}_{-} \mathrm{O}^{-}\right)$of acidic polysaccharides (for example, alginate). Acidic polysaccharides have an excess of $\mathrm{COO}^{-}$groups that have high affinity for binding positive ions.

We concluded that carboxyl groups in the unidentified biofilm polysaccharide chains must be sites at which $\mathrm{FeOOH}$ amorphous nano-precipitates bind, initiating templation and akaganeite crystal formation upon ageing (fig. 5).

Biomineralization of these bacterial filaments has common features with mollusk shell nacre formation: in both cases there is enough evidence to suggest that negatively charged groups along the organic polymers are responsible for the interaction with the positively charged mineral ions, $\mathrm{Fe}^{3+}$ and $\mathrm{Ca}^{2+}$, respectively. In the case of the microbial acidic polysaccharides, negatively charged $\mathrm{COO}^{-}$groups are responsible. Along the acidic glycoproteins in nacre it is believed that the negatively charged amino acids glutamate and aspartate, play an equivalent role (Mann, 1988, 2001; Mann and others, 2000; Weiss and others, 2000; Weiner and Dove, 2003).

Acidic amino acids or polysaccharides with excess carboxyl groups are the most common and most effective cation-binding biopolymers that any organism can assemble to bind mineral precursors and initiate templation.

Analyzing a biomineral from both the mineral and the biopolymer perspective, it is always possible to identify spectral signatures even if the bond sites are not those expected. As shown by the recent experiment on microbial polysaccharide-FeOOH filaments, by XANES analysis of the organic and the mineral components of biominerals, the nature of the organic-inorganic interactions is determined, thereby revealing the beginning of templation at the molecular scale.

\section{XANES Analysis of a Designed Peptide}

The major complication in understanding the formation and templation of biominerals lies in the discovery of multiple proteins in each biomineral. Several of these proteins in combination may play a role in biomineralization. Some exhibit specific binding sites (for example, aspartate and/or glutamate), others have catalytic (Weaver and Morse, 2003) or a stereochemical recognition function (De Yoreo and Dove, 2004).

A class of relatively simple proteins, naturally optimized to bind crystals is antifreeze proteins (AFPs). AFPs provide fish and grass with protection against the freezing effects of polar environments by binding to ice surfaces and inhibiting growth of ice crystals (Madura and others, 1994; Sicheri and Yang, 1995; Zhang and Laursen, 1998). Ice is not generally considered to be a "biomineral", but the AFPs represent the best available structural models for interactions between a peptide and an inorganic surface. Detailed structural hypotheses have been proposed to explain how specific AFP surfaces (from x-ray crystallography or multi-dimensional NMR spectroscopy) bind to specific ice crystal faces. As far as we know, there are no comparable models for interactions between true biominerals and the proteins or other biopolymers that control their formation; indeed, there is no structural information for the relevant proteins by themselves. Therefore, extrapolation from known AFP structures, and current understanding of how AFPs interact with specific ice surfaces may lead to more immediate insights in biomineralization.

Several structural classes of AFPs have been identified; all have relatively simple folding patterns. The simplest are the type-I AFPs, which form a single long $\alpha$-helix with ice-binding side chains (such as the hydroxyl-bearing side chain of threonine) 
aligned along one side. High-resolution structural data for other AFPs suggest that $\beta$-sheet secondary structure can also provide a surface for display of an appropriately organized set of crystal-binding side chains (Leinala and others, 2002).

Evans has recently suggested that perhaps the proteins involved in antifreeze and biomineralization functions are not truly comparable, since the latter tend to be unfolded in the absence of the mineral (Evans, 2003). Recent work of Hamilton and others, however, shows that molecules designed to display arrays of carboxylate side chains designed to share a common orientation can influence the growth of $\mathrm{CaCO}_{3}$ crystals, and that the influence can be rationalized on an atomic scale (Estroff and others, 2004). These results strongly support our approach: as a biomineral model, we analyze synthetic peptides inspired by AFPs, and the interaction of these with ions and nanoparticles in solution.

We designed a 20-residue peptide, $\mathbf{1}$, to be capable of interaction with biomineral surfaces, based on principles manifested by type I AFPs. Peptide $\mathbf{1}$ is designed to adopt an $\alpha$-helical conformation (favored by the numerous alanine (Ala) and glutamine $(\mathrm{Gln})$ residues) that displays a "stripe" of six glutamate $(\underline{\mathrm{Glu}})$ residues along one side. Placing the Glu residues in a repeating pattern $(i, i+3, i+7, i+10, i+14, \ldots)$, the so-called 3,4-repeat, leads to alignment of these residues along one side of the helix. At neutral $\mathrm{pH}$ or higher, the carboxyl side chains of the Glu residues should be ionized; thus, 1 should display a linear array of six anionic carboxylates, allowing it to interact with an array of Ca cations at the surface of a mineral.

\section{Ac-Ala-Glu-Gln-Gln-Glu-Ala-Gln-Gln-Glu-Ala-Ala-Glu-Gln-Ala-Ala- . . .}

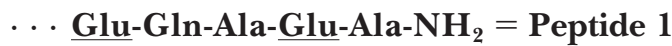

Peptide 1 was analyzed with XANES spectromicroscopy. The results show that binding of $\mathrm{Ca}^{2+}$ ions to the peptide exerts a significant effect on the chemical bonds within the peptide, as demonstrated by the spectral modifications observed at the carbon K-edge.

In figure 6 we present the $\mathrm{C}$ K-edge spectra for peptide 1 with and without $\mathrm{Ca}^{2+}$ ions in solution. The spectra show the effect of Ca-binding on the carboxyl group electronic structure. In particular, the $\mathrm{C}=\mathrm{O}$ peak at $288.4 \mathrm{eV}$ is shifted by $0.2 \mathrm{eV}$ towards higher binding energy, but it is also broadened and its lineshape is altered when peptide 1 binds Ca. The interpretation of spectral signatures in XANES spectroscopy of large molecules ( $>1$ amino acid) is complex, and requires further interpretation. Fitting of the peaks in these two spectra is helpful. In figure 6 we show that the main spectral feature in peptide $\mathbf{1}$ is the $\pi^{*}$ resonance of the $\mathrm{C}=\mathrm{O}$ groups, and that these are best interpreted as superposition of 3 Gaussian peaks.

The peak fitting results show a dramatic difference between bound and unbound carboxyl groups in peptide 1 . Specifically, upon $\mathrm{Ca}^{2+}$ binding, peak 2 is depleted, while peaks 1 and 3 are enhanced. Because carboxyl groups in glutamate are the most likely binding sites in peptide $\mathbf{1}$, and because the most striking differences in the spectra are at the $\mathrm{C}=\mathrm{O}$ spectral signature, it is reasonable to conclude from these results that any peptide, protein, glycoprotein or polysaccharide with excess carboxyl groups can probably be studied by XANES spectroscopy and spectromicroscopy. In particular, the difference between bound and unbound organic molecules in the presence of nanoparticles can be observed with XANES spectroscopy. In addition, this difference can now be observed in situ, within solid, composite, natural biominerals.

Other studies on the sensitivity of XANES to protein structure and folding are currently being conducted. These might reveal that protein folding is altered by mineral binding, yielding yet another component for the interpretation of XANES spectra from biominerals. 
A

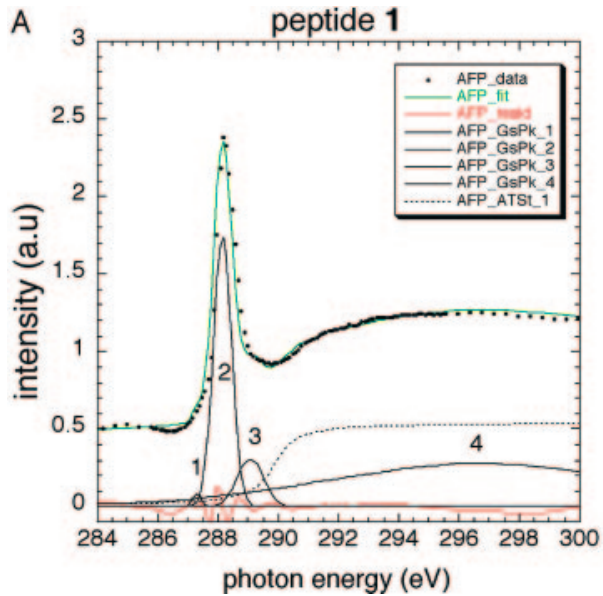

B

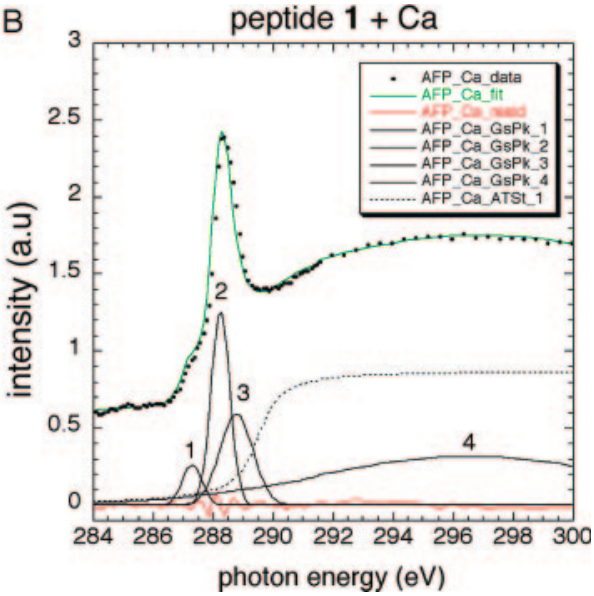

Fig. 6. Carbon K-edge XANES spectra of peptide $\mathbf{1}(\mathbf{A})$ and peptide $\mathbf{1}+\mathrm{Ca}(\mathbf{B})$. Both samples were dried droplets of $100 \mu \mathrm{m}$ solution of peptide $\mathbf{1}$, with and without $681 \mu \mathrm{M} \mathrm{CaCl} \mathrm{C}_{2}$. Note the shift and broadening of the Ca-bound peptide 1 spectrum. Peak fitting in both cases is optimized $\left(\chi^{2}<10^{-4}\right)$ using 4 Gaussian peaks (solid black lines), and 1 arctangent (dotted line). The experimental spectra are reported with black dots and no line. The green line closely approximating the experimental data is the fit obtained with the above components. The red line is the residue, that is, the difference between the experimental data and the fit. The 4 Gaussian peaks are identified by corresponding numbers in the two plots. The first peak at $287.3 \mathrm{eV}$ has minimal intensity in $\mathbf{A}(<0.1$ in normalized intensity arbitrary units), while it is prominent in $\mathbf{B}$. Peak 2 is much more intense in $\mathbf{A}$ than in $\mathbf{B}$ (1.73 vs 1.24, and shifted from 288.1 to $288.2 \mathrm{eV}$ ), while peak 3 is less intense in A than in $\mathbf{B}(0.3$ vs 0.6 , and shifted from 288.8 to $289 \mathrm{eV})$. These 3 peaks are associated with the $\mathrm{C}=\mathrm{O} \pi^{*}$ resonance, while peak 4 , centered at $296.6 \mathrm{eV}$, corresponds to the broad $\sigma^{*}$ resonances of $\mathrm{C}-\mathrm{C}$, mainly in the side chains of peptide 1 .

\section{CONCLUSIONS}

There are many gaps in the present knowledge about biomineral formation and templation mechanisms. XANES studies of molecular structures in biominerals might reveal some of the microscopic details of this phenomenon. If one accepts the hypothesis that composite biominerals form as a result of complex chemical interactions between organic and inorganic matrices, and that the former acts as a template for the latter, then the interface between the two must be analyzed to elucidate templation mechanisms.

Our recent experiments on mineralized microbial filaments and on a synthetic peptide designed to bind $\mathrm{Ca}^{2+}$ represents the first evidence that the organic-inorganic interface can be understood with spectromicroscopy. We look forward to seeing the same nano-analytical approach used by other groups and ours, and extended to reveal the organic-inorganic interface in other biomineral systems.

Once the molecular-scale chemistry of the interface will be elucidated, it might be possible to harness it and synthesize novel biomimetic composite materials that self-assemble and outperform the sum of their components.

\section{ACKNOWLEDGMENTS}

We thank Jill Banfield and Clara Chan for their expert, friendly and continued collaboration, and most importantly for bringing G.D.S. into the exciting adventure of discovering templation of akaganeite crystal fibers. We also thank Brad Frazer and Marco Girasole for their collaboration in the spectromicroscopy experiments, and Ben Gilbert for the critical review of this manuscript and the routines for peak fitting. Funding for this work was provided by the UW-Graduate School, Department of Physics and Comprehensive Cancer Center. Work in the Gellman laboratory was 
supported by NSF-CHE0140621. M.A.S. was supported in part by an NIH Molecular Biophysics Training Grant (GM08293). X-PEEM experiments were performed at the UW-Synchrotron Radiation Center, supported by NSF-DMR 0084402. We would also like to thank two anonymous reviewers whose reviews led to an improved manuscript.

\section{REFERENCES}

Addadi, L., and Weiner, S., 1997, Biomineralization: A pavement of pearl: Nature, 389, p. 912-915.

Banfield, J. F., and Nealson, K. H., Editors, 1997, Geomicrobiology: interactions between microbes and minerals: Washington, D. C., Mineralogical Society of America, Reviews in Mineralogy, 35, 448 p.

Banfield, J. F., Welch, S. A., Zhang, H., Ebert, I. T., and Penn, R. L., 2000, Aggregation-based crystal growth and microstructure development in natural iron oxyhydroxide biomineralization products: Science, 289 , p. 751-754.

Beauchemin, S., Hesterberg, D., Chou, J., Beauchemin, M., Simard, R. R., and Sayers, D. E., 2003, Speciation of phosphorus in phosphorus-enriched agricultural soils using X-ray absorption near-edge structure spectroscopy and chemical fractionation: Journal of Environmental Quality, 32(5), p. 1809-1819.

Benfatto, M., Longa, S. Della, Natoli, C. R., 2003, The MXAN procedure: a new method for analysing the XANES spectra of metalloproteins to obtain structural quantitative information: Journal of Synchrotron Radiation, 10, p. 51-57.

Bozek, J. D., Bancroft, G. M., Cutler, J. N., and Tan, K. H., 1990, Vibrationally resolved core-level photoelectron spectroscopy: $\mathrm{Si} 2 \mathrm{p}$ levels of $\mathrm{SiH}_{4}$ and $\mathrm{SiF}_{4}$ molecules: Physical Review Letters, 65(22), p. 2757-2760.

Carravetta, V., Plashkevych, O., and Ågren, H., 1998, A theoretical study of the near-edge x-ray absorption spectra of some larger amino acids: Journal of Chemical Physics, 109, p. 1456-64.

Chan*, C. S., De Stasio*, G., Welch, S. A., Girasole, M., Frazer, B. H., Nesterova, M. V., Fakra, S., and Banfield, J. F., 2004, Microbial polysaccharides template the formation of akaganeite nanocrystal fibers: *These authors contributed equally, Science, 303, p. 1656-58

Currey, J. D., 1977, Mechanical properties of mother of pearl in tension: Proceedings of the Royal Society of London, B 196, p. 443-463.

De Stasio, G., Casalbore, P., Pallini, R., Gilbert, B., Sanita', F., Ciotti, M. T., Rosi, G., Festinesi, A., Larocca, L. M., Rinelli, A., Perret, D., Mogk, D. W., Perfetti, P., Mehta, M. P., and Mercanti, D., 2001, Gadolinium in Human Glioblastoma Cells for Gadolinium Neutron Capture Therapy: Cancer Research, 61, p. $4272-4277$.

De Stasio, G., Dunham, D., Tonner, B. P., Mercanti, D., Ciotti, M.T., Coluzza, C., Perfetti, P., and Margaritondo, G., 1993, Aluminum in Rat Cerebellar Neural Cultures: NeuroReport, 4, p. 1175-1178.

De Stasio, G., Frazer, B. H., Gilbert, B., Richter K. L., and Valley, J. W., 2003 Compensation of charging in X-PEEM: a successful test on mineral inclusions in 4.4 Ga old zircon: Ultramicroscopy, 98, p. 57-62.

De Stasio, G., Mercanti, D., Ciotti, M. T., Droubay, T. C., Perfetti, P., Margaritondo, G., and Tonner, B. P. 1996, Synchrotron Spectromicroscopy of Cobalt Accumulation in Granule Cells, Glial Cells and GABAergic Neurons: Journal of Physics, D29, p. 259-262.

De Yoreo, J. J., and Vekilov, P. G., 2003, Principles of Crystal Nucleation and Growth, in Dove, P. M., De Yoreo, J. J., and Weiner, S., editors, Biomineralization: Washington, D. C., Mineralogical Society of America, Reviews in Mineralogy and Geochemistry, v. 54, p. 57-93.

De Yoreo, J. J., and Dove, P. M., 2004, Shaping Crystals with Biomolecules: Science, 306, p. 1301-1302.

Estroff, L. A., Incarvito, C. D., and Hamilton, A. D., 2004, Design of a synthetic foldamer that modifies the growth of calcite crystals: Journal of the American Chemical Society, 126, p. 2-3.

Evans, J. S., 2003, 'Apples' and 'oranges': comparing the structural aspects of biomineral- and ice-interaction proteins. Current Opinion in Colloid and Interface Science, 8, p. 48-54.

Fitts, J. P., Persson, P., Brown, G. E. Jr., Parks, G. A., 1999, Structure and Bonding of Cu(II)-Glutamate Complexes at the gamma- $\mathrm{Al}_{2} \mathrm{O}_{3}$-Water Interface: Journal of Colloid Interface Science, 220, p.133-147.

Fortin, D., Ferris, F. G., and Beveridge, T. J., 1997, Surface-mediated mineral development by bacteria, in Banfield, J. H., and Nealson, K. H., editors, Geomicrobiology: interactions between microbes and minerals: Washington, D. C., Mineralogical Society of America, Reviews in Mineralogy, 35, p. 161-177.

Frazer, B. H., Girasole, M., Wiese, L. M., Franz T., and De Stasio, G., 2004, Spectromicroscope for the PHotoelectron Imaging of Nanostructures with X-rays (SPHINX): performance in biology, medicine and geology: Ultramicroscopy, 99, p. 87-94.

Gilbert, B., Perfetti, L., Fauchoux, O., Redondo, J., Baudat, P. A., Andres, R., Neumann, M., Steen, S., Gabel, D., Mercanti, Delio, Ciotti, M. Teresa, Perfetti, P., Margaritondo, G., and De Stasio, G., 2000, The Spectromicroscopy of Boron in Human Glioblastomas following Administration of BSH: Physical Review, E 62, p. 1110-1118.

Gilbert, B., Frazer, B. H., Naab, F., Fournelle, J., Valley J. W., and De Stasio, G., 2003, X-ray absorption spectroscopy of silicates for in situ sub-micrometer mineral identification: American Mineralogist, 88, p. 763-769.

Glasauer, S., Langley, S., and Beveridge, T. J., 2002, Intracellular Iron Minerals in a Dissimilatory IronReducing Bacterium: Science, 295, p. 117-119.

Jackson, A. P., Vincent, J. F., and Turner, R. M., 1988, The mechanical design of nacre: Proceedings of the Royal Society of London, B 234, p. 415-440.

Kaznacheyev, K., Osanna, A., Jacobsen, C., Plashkevych, O., Vahtras, O., Ågren, H., Carravetta, V., and Hitchcock, A. P., 2002, Innershell Absorption Spectroscopy of Amino Acids: Journal of Physical Chemistry A, 106, p. 3153-3168. 
Kilcoyne, A. L. D., Tyliszczak, T., Steele, W. F., Fakra, S., Hitchcock, P., Franck, K., Anderson, E., Harteneck, B., Rightor, E. G., Mitchell, G. E., Hitchcock, A. P., Yang, L., Warwick, T., and Ade H., 2003, Interferometer-controlled scanning transmission X-ray microscopes at the Advanced Light Source: Journal of Synchrotron Radiation, 10, p. 125-136.

Labrenz, M., Druschel, G. K., Thomsen-Ebert, T., Gilbert, B., Welch, S. A., Kemner, K. M., Logan, G. A., Summons, R. E., De Stasio, G., Bond, P. L., Lai, B., Kelly, S. D., and Banfield, J. F., 2000, Formation of Sphalerite (ZnS) Deposits in Natural Biofilms of Sulfate-Reducing Bacteria: Science, 290, p. 1744-1747.

Lawrence, J. R., Swerhone, G. D., Leppard, G. G., Araki, T., Zhang, X., West, M. M., and Hitchock, A. P., 2003, Scanning transmission X-ray, laser scanning, and transmission electron microscopy mapping of the exopolymeric matrix of microbial biofilms: Applied and Environmental Microbiology, 69, p. 55435554.

Leinala, E. K., Davies, P. L., and Jia, Z., 2002, Crystal structure of a b-helical antifreeze protein points to a general ice binding model: Structure, 10 , p. 619-627.

Lerotic, M., Jacobsen, C., Schafer, T., and Vogt, S., 2004, Cluster analysis of soft X-ray spectromicroscopy data: Ultramicroscopy, 100, p. 35-57.

Lopez-Garcia, P., Duperron, S., Philippot, P., Foriel, J., Susini, J., and Moreira, D., 2003, Bacterial diversity in hydrothermal sediment and epsilonproteobacterial dominance in experimental microcolonizers at the Mid-Atlantic Ridge: Environonmental Microbiology, 5, p. 961-976.

Lower, S. K., Hochella, M. F., Jr., and Beveridge, T. J., 2001, Bacterial Recognition of Mineral Surfaces: Nanoscale Interactions Between Shewanella and -FeOOH: Science, 292, p. 1360-1363.

Madura, J. D., Wierzbicki, A., Harrington, J. P., Maughon, R. H., Raymond, J. A., and Sikes, C. S., 1994 Interactions of the D- and L-Forms of Winter Flounder Antifreeze Peptide with the $\{201\}$ Planes of Ice: Journal of the American Chemical Society, 116, p. 417-418.

Mann, S., 1988, Molecular recognition in biomineralization: Nature, 332, p. 119-124.

2001, Biomineralization: Principles and Concepts in Bioinorganic Materials Chemistry: Oxford, United Kingdom, Oxford University Press, 198 p.

Mann, K., Weiss, I. M., Andre, S., Gabius, H. J., and Fritz, M., 2000, The amino-acid sequence of the abalone (Haliotis laevigata) nacre protein perlucin, European Journal of Biochemistry FEBS, 267, p. 5257-5264

Mount, A. S., Wheeler, A. P., Paradkar, R. P., and Snider, D., 2004, Hemocyte-Mediated Shell Mineralization in the Eastern Oyster: Science, 304, p. 297-300.

Myneni, S. C. B., 2002a, Formation of stable chlorinated hydrocarbons in weathering plant material: Science, 295, p. $1039-1041$.

_ 2002b, Soft X-ray spectroscopy and spectromicroscopy studies of organic molecules in the environment, in Fenter, P. A., Rivers, M. L., Sturchio, N. C., Sutton, S. R., editors, Applications of Synchrotron Radiation in Low Temperature Geochemistry and Environmental Science: Reviews in Mineralogy and Geochemistry, v. 49 , p. $485-579$.

Myneni, S. C., Tokunaga, T. K. and, Brown, G. E. Jr., 1997, Abiotic Selenium Redox Transformations in the Presence of Fe(II,III) Oxides: Science, 278, p. 1106-110.

Myneni, S. C. B., Brown, J. T., Martinez, G. A., and Meyer-Ilse, W., 1999, Imaging of humic substance macromolecular structures in water and soils: Science, 286, p. 1335-1337.

Pickering, I. J., Prince, R. C., Salt, D. E., and George, G. N., 2000, Quantitative, chemically specific imaging of selenium transformation in plants: Proceedings of the National Academy of Sciences of the United States of America, 97, p. 10717-10722.

Schäffer, T. E., Ionescu-Zanetti, C., Proksch, R., Fritz, M., Walters, D. A., Almqvist, N., Zaremba, C. M., Belcher, A. M., Smith, B. L., Stucky, G. D., Morse, D. E., and Hansma, P. K., 1997, Does Abalone Nacre Form by Heteroepitaxial Nucleation or by Growth through Mineral Bridges?: Chemistry of Materials, 9 , p. 1731-1740.

Sicheri, F., and Yang, D. S. C., 1995, Ice-Binding Structure and Mechanism of an Antifreeze Protein from Winter Flounder: Nature, 375, p. 427-431.

Stöhr, J., 1992, NEXAFS Spectroscopy: Berlin, Springer-Verlag, 403 p.

Sturchio, N. C., Antonio, M. R., Soderholm, L., Sutton, S. R., and Brannon, J. C., 1998, Tetravalent Uranium in Calcite: Science, 281, p. 971-973.

Tang, Z., Kotov, N. A., Magonov, S., and Ozturk, B., 2003, Nanostructured artificial nacre: Nature Materials, 2, p. 413-418.

Templeton, A. S., Ostergren, J. D., Trainor, T. P., Foster, A. L., Traina, S. J., Spormann, A., and Brown, G. E. Jr., 1999, XAFS and XSW study of the distribution of $\mathrm{Pb}(\mathrm{II})$ sorbed to biofilms on alpha- $\mathrm{Al}_{2} \mathrm{O}_{3}$ and alpha-FeOOH surfaces: Journal of Synchrotron Radiation, 6, p. 642-644.

Tyliszczak, T., Warwick, T., Kilcoyne, A. L. D., Fakra, S., Shuh, D. K., Yoon, T. H., Brown, G. E., Jr., Andrews, S., Chembrolu, V., Strachan, J., and Acremann, Y., 2004, Soft X-ray Scanning Transmission Microscope Working in an Extended Energy Range at the Advanced Light Source: AIP Conference Proceedings, May 12, 2004, v. 705, p. 1356-1359.

Weaver, J. C., and Morse, D. E., 2003, Molecular biology of demosponge axial filaments and their roles in biosilicification: Microscopy Research and Technique, 62, p. 356-67.

Weiner, S., and Dove, P. M., 2003, An Overview of Biomineralization Processes and the Problem of the Vital Effect, in Dove, P. M., De Yoreo, J. J., and Weiner, S., editors, Biomineralization: Washington, D. C., Mineralogical Society of America, Reviews in Mineralogy and Geochemistry, v. 54, p. 1-29.

Weiss, I. M., Kaufmann, S., Mann, K., and Fritz, M., 2000, Purification and characterization of perlucin and perlustrin, two new proteins from the shell of the mollusk Haliotis laevigata: Biochemistry and Biophysics Research Communications, 267, p. 17-21.

Wilde, S. A., Valley, J. W., Peck, W. H., and Graham, C. M., 2001, Evidence from detrital zircons for the existence of continental crust and oceans on the Earth 4.4 Gyr ago: Nature, 409, p. 175-178 
Zawislanski, P. T., Benson, S. M., Terberg, R., and Borglin, S. E., 2003, Selenium speciation, solubility, and mobility in land-disposed dredged sediments: Environmental Science and Technology, 37(11), p. 241520.

Zhang, W., and Laursen, R. A., 1998, Structure-Function Relationships in a Type I Antifreeze Polypeptide: The Role of Threonine Methyl and Hydroxyl Groups in Antifreeze Activity: The Journal of Biological Chemistry, 273, p. 34806-34812. 